\title{
Column Chromatography
}

Column chromatography is a technique in which a glass column filled with adsorbent (i.e., silica gel, alumina, or C18 reversed-phase packing) is used for the purification of large quantities (milligrams to grams) of reaction product mixtures. As with thin-layer chromatography (TLC; APPENDIX 3D), the adsorbent used varies depending upon the type of separation to be carried out. In any case, it is often useful to analyze the mixture by thin-layer chromatography prior to column chromatography. For example, if suitable conditions using silica gel TLC plates are found, then the silica gel should be used as the adsorbent for the column chromatography. Separations carried out using C18 reversedphase adsorbent are time-consuming because elution of water-containing solvent systems is generally slow. For these types of separations, it is best to use a medium- or high-pressure chromatography system (MPLC or HPLC). Consequently, this discussion will focus only on those separations carried out using silica gel or alumina.

After the column has been packed with the appropriate adsorbent and eluent (see Support Protocol), the crude mixture of compounds to be separated is loaded onto the top of the adsorbent layer, and then flushed downward through the column (see Basic Protocol). The procedure can be carried out using gravity to pull the solvent down the column, or by forcing the solvent through the column using a technique known as flash chromatography. Microscale chromatography is also possible (see Alternate Protocol). As with TLC, each compound "sticks" to the adsorbent differently. Thus, the mixture is separated as the solvent elutes through the column. The individual compounds exit the end of the column and are collected in separate tubes or flasks, analyzed by TLC, and isolated. Generally, purifications of $>95 \%$ can be achieved.

\section{COLUMN CHROMATOGRAPHY}

After the column is packed (see Support Protocol), it is time to load the crude mixture of compounds to be separated onto the top layer of the column. If a gradient eluent is being used to separate the mixture, dissolve the crude mixture in the least polar solvent used in the gradient, using as little solvent as possible. If the crude mixture will not dissolve completely in the chosen solvent system, it may be possible to dissolve the mixture in a different, more suitable solvent (consult someone skilled in this technique). Generally, loading the crude mixture onto the column using solvents other than the chosen eluent should be avoided, as it may affect the separation.

\section{Materials}

Crude mixture

Eluent

Chromatography column, packed (see Support Protocol)

Flash chromatography apparatus (optional): $250 \mathrm{~mL}$ solvent reservoir, 35/20 spherical joint with appropriate flow controller (Chemglass), and air source

Additional reagents and equipment for thin-layer chromatography (TLC; APPENDIX 3D)

\section{Load column}

1. Dissolve the crude mixture of compounds in the chosen eluent. Use a Pasteur pipet to load the mixture onto a packed chromatography column. With the stopcock closed, let the mixture run slowly down the inner side of the column, continually moving the

Contributed by C.L.F. Meyers

Current Protocols in Nucleic Acid Chemistry (2000) A.3E.1-A.3E.7

Copyright $\odot 2000$ by John Wiley \& Sons, Inc.
BASIC PROTOCOL

Synthesis of Unmodified Oligonucleotides A.3E.1 Supplement 3 
pipet tip around the inner circumference of the column as the mixture is released from the pipet.

IMPORTANT NOTE: Be careful not to disturb the top layer of sand.

Moving the pipet tip will ensure that the mixture is evenly deposited on the top of the column.

2. Open the stopcock and allow the solvent to drain into a flask until the upper level of solvent reaches the top layer of sand.

IMPORTANT NOTE: Do not let the solvent level run below the top layer of sand.

3. Using a Pasteur pipet, rinse the sides of the column with a small amount of eluent (use as little solvent as necessary). Again, drain the solvent until the upper level of solvent reaches the top layer of sand.

\section{Assemble apparatus}

4a. Conventional chromatography: Fill the column with the chosen eluent.

IMPORTANT NOTE: Be careful not to disturb the top layer of sand.

4b. Flash chromatography: Attach the solvent reservoir to the top of the column using the appropriate clamp. Attach a compatible flow controller to the top of the solvent reservoir (Fig. A.3E.1).

The use of a solvent reservoir is optional for this procedure.

The flow controller is equipped with a hose that can be hooked up to a source of air or nitrogen. For most separations, the laboratory air hose is sufficient for supplying the appropriate amount of pressure. Air pumps can also be used to supply gas pressure.

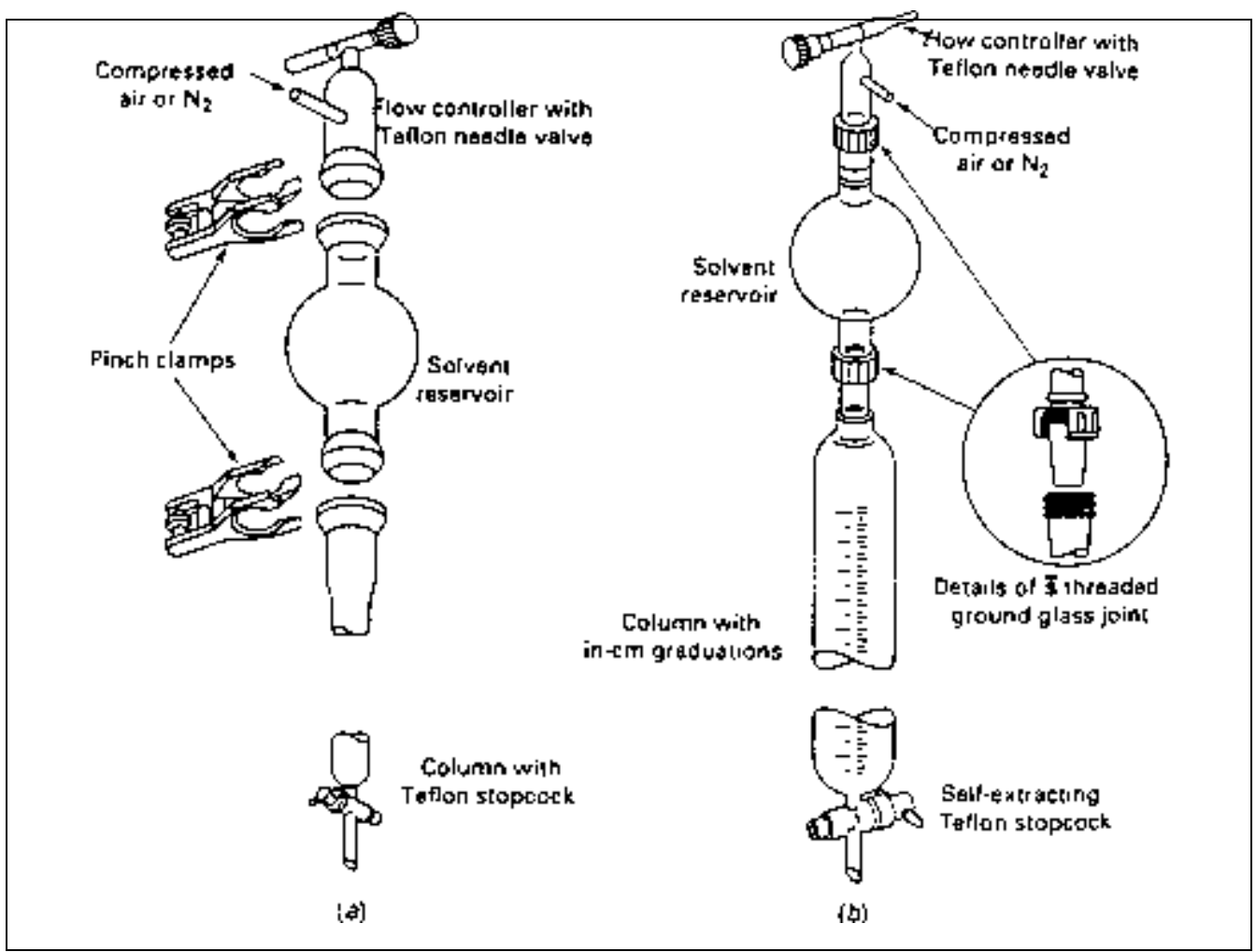

Column Chromatography

Figure A.3E.1 Professional flash chromatography columns. (A) Conventional. (B) Screw-thread. Reprinted from Mayo et al. (1994) with permission from John Wiley \& Sons. 
5. Assemble test tubes and rack for fraction collection from the column.

\section{Separate compounds and collect fractions}

6a. Conventional chromatography: Open the stopcock and allow the solvent to elute by gravity from the bottom of the column.

6b. Flash chromatography: Open the stopcock and flow controller completely. Turn on the gas source and adjust the flow controller until the solvent elutes from the bottom of the column at the desired rate.

Slower elution ( 1 drop per sec) may be necessary for the separation of compounds with similar $R_{f}$ values $\left(\Delta R_{f}<0.1\right)$. Compounds whose $R_{f}$ values are very different $\left(\Delta R_{f}>0.1\right.$ to 0.15 ) can be separated easily with faster elution (5 to 10 drops per sec).

7. Let the eluent run through the column and collect the different fractions in test tubes. Do not let the solvent run below the top layer of sand. Add more solvent to the column by stopping the air pressure (flash chromatography), closing the stopcock, removing the flow controller (flash chromatography), and adding more solvent to the solvent reservoir.

If using a particularly volatile solvent (e.g., diethyl ether or methylene chloride), the solvent may evaporate as it elutes from the column, leaving crystals of compound on the tip of the stopcock. If this occurs, simply dissolve/rinse the crystals into the test tube, and analyze the fraction by $T L C$.

8. As the solvent elutes down the column, collect fractions in test tubes or small flasks. Analyze each fraction by TLC (APPENDIX $3 D$ ) to determine the point at which the desired compound(s) elute from the column, using one TLC plate for 4 to 6 fractions, depending upon the width of the TLC plate and the size of the developing chamber.

In most cases, the same spotter can be used during the entire chromatography, as long as it is cleaned after loading each fraction onto the TLC plate. The TLC for each fraction will also give an idea of the purity of the compound. If running a silica gel column, compounds with higher $R_{f}$ values will elute from the column first.

If the compounds are colored, the separation can be observed as it takes place down the column; however, many organic compounds are colorless, and the progress of the chromatography must be followed using TLC.

9. Use the $R_{\mathrm{f}}$ value to obtain a rough estimation of the amount of solvent it will take to elute a particular compound.

For example, if a compound has an $R_{f}$ of 0.5 , it will migrate halfway down the column during the elution of one column volume of solvent. A column volume is the volume of solvent equal to the volume of adsorbent. Using the different $R_{f}$ values of the various compounds that are being separated, the number of column volumes it will take to elute every compound using a particular solvent system can be estimated.

\section{Optimize chromatography}

10. Evaluate the need to change the polarity of the eluent.

After the first compound has eluted from the silica gel or alumina column, the polarity of the solvent may need to be increased to avoid unnecessary use of large solvent volumes and long separation times. The composition and polarity of the new solvent system will depend upon the type of separation being carried out. TLC can be used as a way to predict which will be the best solvent to use. If it is decided that a gradient solvent system is to be used during the chromatography, the conversion from the initial solvent system to a more polar solvent system should be made gradually. For example, if adjusting the solvent system from 5\% methanol in chloroform to $15 \%$ methanol in chloroform, the adjustment should be made incrementally. To do this, change the solvent system to $8 \%$ methanol in chloroform

Synthesis of Unmodified Oligonucleotides

\section{A.3E.3}


ALTERNATE PROTOCOL

SUPPORT PROTOCOL

Column Chromatography

and elute one column volume of the new solvent system. Change the solvent system to $12 \%$ methanol in chloroform and, again, elute one column volume of solvent. Finally, change the solvent system to the desired $15 \%$ methanol in chloroform and pass enough solvent through the column to elute the desired compound from the column. The number of column volumes eluted during the conversion from one solvent system to another is dependent upon the nature of the separation.

11. To change the eluent, let the old solvent run down to the top sand layer and close the stopcock. Slowly add the new solvent to the top of the column.

IMPORTANT NOTE: Be careful not to disturb the sand layer.

12. After analyzing each fraction by TLC, combine fractions containing the same pure compound and strip away the solvent using a rotary evaporator.

CAUTION: Do not use a flame to evaporate organic solvents.

\section{MICROSCALE CHROMATOGRAPHY}

Flash column chromatography can be carried out on small quantities (milligram amounts) of crude product mixtures using a Pasteur pipet (short tip) as a column. The column is packed (see Support Protocol) and loaded (see Basic Protocol) in the same manner as the large-scale column. Compound elution can be accomplished by pushing the eluent through the column using a pipet bulb or an air hose.

\section{PACKING A CHROMATOGRAPHY COLUMN}

Before carrying out column chromatography, the glass column must be packed with the appropriate adsorbent and a suitable solvent (Fig. A.3E.2). There are two methods for packing a column: wet packing and dry packing. Wet packing can be messy, but this technique works every time and is preferred for packing silica gel columns. Dry packing often results in the formation of air bubbles that can be difficult to remove. When this happens, the column must be repacked; however, when alumina is used as an adsorbent, the preferred method is dry packing, as wet packing with alumina requires making a slurry that is difficult to pour.

Often, it is necessary to carry out column chromatography using a gradient eluent. This means that the polarity of the solvent system may need to be changed during the chromatography so that both nonpolar and polar compounds can be eluted from the column. To determine if this is necessary, analyze the mixture by TLC (APPENDIX $3 D$ ). If the compounds to be separated have widely different $R_{\mathrm{f}}$ values, more than one solvent system may be necessary in order to elute both compounds adequately. If chromatography using a gradient eluent is to be used, it will be necessary to pack a silica gel or alumina column using the least polar solvent in the gradient.

\section{Materials}

Eluent

Adsorbent (e.g., mesh silica gel; Fisher)

Glass wool

Glass column with ground glass or threaded joint at the top and stopcock at the bottom

Fine sand

Stiff rubber tube or rubber stopper attached to a handle (e.g., wooden or glass rod) 


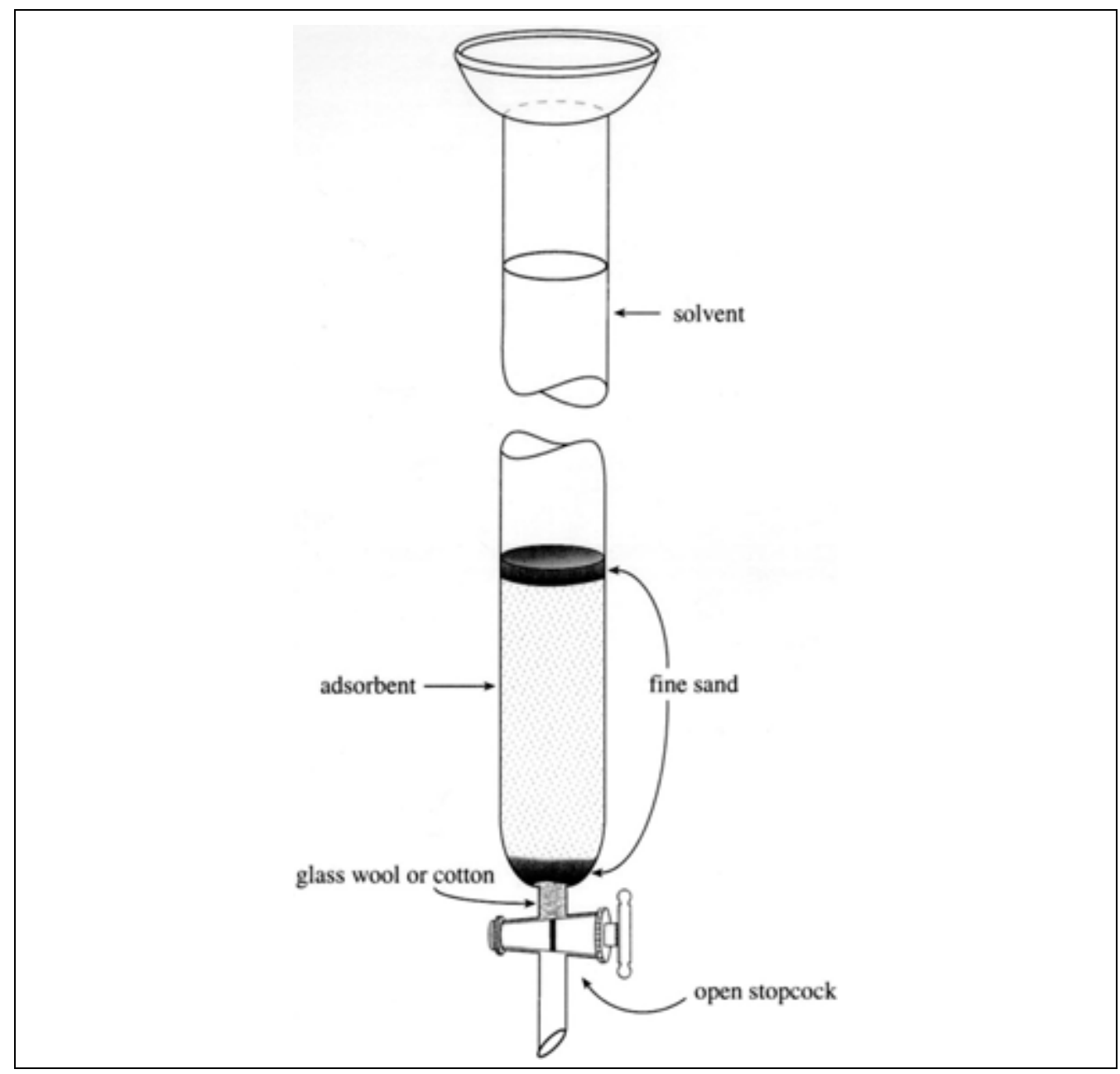

Figure A.3E.2 Packing a chromatography column.

\section{Prepare column and adsorbent}

1. Place a small wad of glass wool just above the closed stopcock in the glass column. Push the plug of glass wool down onto the top of the stopcock using a long rod.

A glass column made specifically for column chromatography, or an ordinary buret, can be used as the column.

If the plug is too loose, adsorbent will leak through. If the plug is too dense, the eluent will flow very slowly through the column, increasing the time it takes to carry out the column chromatography.

2. Clamp the column vertically to a ring stand inside a hood, or to the grid work inside the hood if possible. Leave enough room at the bottom of the column for a test tube rack or flask.

3. To insure that no adsorbent leaks from the column, add enough fine sand to cover the plug of glass wool.

4. Add the chosen eluent to a height of $\sim 1$ in. $(2.56 \mathrm{~cm})$ above the layer of sand. Make sure that the stopcock is closed before adding the eluent.

This will prevent a disturbance of the sand layer when the adsorbent is finally added.

5. Weigh out the appropriate amount of adsorbent into a beaker. 
For routine chromatographic separations, $\sim 40 \mathrm{~g}$ of adsorbent per $1 \mathrm{~g}$ of crude mixture works well. The exact amount of adsorbent to use will depend upon the degree of separation observed by TLC (Still et al., 1978). Commonly used adsorbents are commercially available from most scientific supply companies (e.g., Fisher). Many adsorbents are available in a variety of grades. The optimum adsorbent grade will depend upon the type of separation and adsorbent being used. Silica gel with a pore size of 230 to 400 mesh will be sufficient for routine chromatographic separations. If necessary, the adsorbent may be activated by heating (i.e., removing water) prior to use. Furthermore, silica gel is weakly acidic, so it may be necessary to deactivate it by treatment with dilute amine prior to and during the separation of weakly basic compounds such as aliphatic amines. For a complete guide to adsorbents and their particular applications, refer to the CRC Handbook of Chromatography (Zweig and Sherma, 1972).

\section{Pour column}

Wet packing columns:

6a. Add enough of the chosen eluent to a preweighed amount of adsorbent (step 5) to make a slurry that is easy to pour ( $\sim 5 \mathrm{~mL}$ eluent/g adsorbent). Use a spatula to mix the slurry. Be sure that all of the adsorbent is wet and that there are no air bubbles in the slurry.

7a. Slowly pour the slurry down the inner edge of the column.

IMPORTANT NOTE: If the pouring is too quick, the layer of sand at the bottom of the column will be disturbed and the sand will mix with the adsorbent.

8a. Rinse the sides of the column with the eluent and allow the adsorbent to settle. Proceed to step 9.

Dry packing alumina columns:

6b. Fill the column halfway with the chosen eluent.

7b. Slowly add the dry adsorbent to the column. As the adsorbent is added, gently tap the sides of the column with a stiff rubber tube or a rubber stopper attached to the end of a handle (i.e., glass or wooden rod).

Tapping the sides of the column will ensure that the adsorbent settles to the bottom of the column evenly. If the adsorbent is added too quickly, heat may be liberated as the adsorbent absorbs the solvent. If this happens, the solvent may boil and result in a change in the solvent composition of the eluent (the eluent may be a mixture of two or more solvents). If this happens, the column must be repacked.

8b. Make sure there are no air bubbles or cracks in the column after dry packing. Remove air bubbles by tapping the sides of the column with a stiff rubber tube or a rubber stopper attached to the end of a handle until they rise to the top of the adsorbent layer.

Some air bubbles are difficult to remove. Columns containing air bubbles or cracks will not be effective for separating mixtures of compounds. If air bubbles cannot be removed, the column should be repacked.

9. After the column has been packed, open the stopcock and allow the eluent to drain through the column into a clean flask.

IMPORTANT NOTE: Do not let the solvent drop below the upper level of adsorbent.

The eluent that is collected can be reused during the chromatography.

10. Tap the sides of the column with a stiff rubber tube or a rubber stopper attached to the end of a handle. This will result in additional settling of the adsorbent, leaving a small amount of solvent on the upper level of adsorbent. Drain this small amount of 
solvent into the flask until it reaches the upper level of adsorbent. Tap the column again and drain the residual solvent until the adsorbent is tightly packed.

Tapping the column aids in tightly packing the adsorbant. This technique also ensures that the upper level of adsorbent (the "baseline" of the column) is even.

11. Add a small amount of fine sand to the upper level of adsorbent $(\sim 0.5 \mathrm{~cm})$. Using eluent, rinse down any dry sand sticking to the edges of the column. Tap the sides of the column with a stiff rubber tube or a rubber stopper attached to the end of a handle to ensure that the upper layer of sand is even.

If the adsorbent is not tightly packed, the upper level of adsorbent and the top layer of sand may mix. This will produce an uneven "baseline" for the chromatography. If this occurs, the column should be repacked.

\section{LITERATURE CITED}

Mayo, D.W., Pike, R.M., and Trumper, P.K. 1994. Microscale Organic Laboratory: With Multistep and Multiscale Syntheses, 3rd ed. John Wiley \& Sons, New York.

Still, C.W., Kahn, M., and Mitra, A. 1978. Rapid Chromatographic technique for preparative separations with moderate resolution. J. Org. Chem. 43:2923-2925.

Zweig, G. and Sherma, J. 1972. CRC Handbook of Chromatography, Volumes I and II. CRC Press, Cleveland, Ohio.

Contributed by C.L.F. Meyers

Purdue University

West Lafayette, Indiana 